\title{
A study of accidental ingestion of hydrocarbons in children in a medical college hospital in central Kerala
}

\author{
Sunil Kumar M.N. ${ }^{1}$, Parvathy V.K. ${ }^{2}$ \\ ${ }^{1}$ Dr Menon Narayanankutty Sunilkumar , ${ }^{2}$ Dr Vadakut Krishnan Parvathy, Both affiliated with Department of Pediatrics, \\ Amala Institute of Medical Sciences, Amala Nagar, Thrissur, Kerala, India.
}

Address for Correspondence: Dr. Menon Narayanankutty Sunil Kumar, Assistant Professor, Department of Pediatrics, Amala Institute of Medical Sciences, Amala Nagar, Thrissur, Kerala, India, E-mail: sunilsree99@ yahoo.co.in

\begin{abstract}
Background: The accidental ingestion of various chemicals especially the hydrocarbons are seen worldwide in the paediatric population. Inspite of all awareness programmes in the community hydrocarbons especially petrol, diesel, turpentine and kerosene are always in the reach of children. The side effects and clinical spectrum is alarming after ingestion. So it is vital to prevent hydrocarbon ingestion. Objective: To understand the clinical profile of accidental ingestion of hydrocarbons (AIH) in children, assess the radiological changes and treatment. Materials and Methods: The retrospective study was conducted analysing the hospital records of children hospitalized between January $1^{\text {st }} 2010$ and December $31^{\text {st }} 2015$ with accidental poisoning due to various causes in the paediatric intensive care unit (PICU) with special reference to AIH. A standard proforma included age, sex of the children, types of poisoning agents including hydrocarbons (HC), clinical presentations and treatment given. Results: In the PICU out of a total of 5806 patients admitted, 401 (6.9\%) were due to acute poisoning. Among them AIH was noted in 118 (29.4\%) patients. These children were admitted initially in the PICU stabilized and there was no mortality following AIH during the period of study. Conclusion: AIH is a common cause of poisoning in children. The main reason is the easy availability in the house itself due to various reasons. The morbidity and mortality can be prevented by education of the society especially the care takers of the children in the community.
\end{abstract}

Key words: Poisons, Accidental childhood ingestion, Hydrocarbons, Petrol, Diesel, Turpentine

\section{Introduction}

Accidental ingestion of poisons in children is a problem in the developing as well as the developed countries [1]. Accidental ingestion of hydrocarbons (AIH) is very common in children [1,2]. There are many reports of $\mathrm{AIH}$ and are usually following inhalations or ingestion. Hydrocarbons (HC) are a large and diverse group of substances which are found in the houses itself and children are an easy prey to AIH because of their inquisitiveness.

In our study HCs such as petrol, diesel, turpentine and kerosene were seen to be ingested. HC poisoning account for about $5 \%$ of all accidental ingestion in paediatric population and infants and younger children are affected [3]. This study was conducted to understand the clinical profile of AIH in children, assess the radiological changes and treatment.

Manuscript received: $24^{\text {th }}$ March 2016

Reviewed: $4^{\text {th }}$ April 2016

Author Corrected; $18^{\text {th }}$ April 2016

Accepted for Publication: $30^{\text {th }}$ April 2016

\section{Materials and Methods}

The retrospective study was conducted analysing the hospital records of children hospitalized between January $1^{\text {st }} 2010$ and December $31^{\text {st }} 2015$ with accidental poisoning due to various causes in the paediatric intensive care unit (PICU) of the medical college. The medical college is located in the central part of Kerala state and caters to a large population from surrounding districts. As it is a tertiary level care centre the PICU receives many children with various diseases and those that present with acute poisoning are in large numbers. The cases were analysed with special reference to AIH. A standard proforma included age, sex of the children, types of poisoning agents including $\mathrm{HCs}$, clinical presentation and treatment given. Also a proper history of the route of poisoning, time of admission of these children after ingestion, socioeconomic status of the family (according to the modified Kuppuswamy scale) and the treatment outcome were analysed. Relevant investigations including complete hemogram, chest $\mathrm{x}$ ray were done in 
these cases with AIH. Blood gas analysis was also done in hypoxic patients following AIH. Inclusion criteria of the study were children with definite history of AIH especially HCs such as petrol, diesel, turpentine and kerosene. Children who are having disorders of developmental delay such as cerebral palsy, neuro degenerative diseases, with encephalopathies and neuropathies were excluded. Accidental ingestion with other substances apart from HCs was also excluded. The study design was approved by Institutional Ethics Research Committee.

\section{Results}

All the children with accidental ingestion of poisons were admitted initially in the PICU of the medical college. In these children $401(6.9 \%)$ were due to acute poisoning out of a grand total of 5806 admissions in the PICU. AIH was noted in $118(29.4 \%)$ of these children. Among the HCs accidental ingestion due to diesel was seen in only 2 (1.7\%) children, due to petrol in $4(3.4 \%)$, following turpentine ingestion $7(6 \%)$, kerosene $91(22.7 \%)$ and miscellaneous such as cleansing solvents and others in $14(11.9 \%)$ children (Table 1). Gender wise distribution revealed that male children were $67.8 \%$ and females $35.2 \%$ in the study of AIH. Among the children with AIH majority $54(45.8 \%)$ were in the age group between 2 to 3 years, 4 less than 1 year (3.3\%), 35 were 1-2 years (29.7\%), 11 were (9.3\%) 3-4 years, 5 cases were (4.2\%) 4-5 years $2(1.7 \%)$ each in 5-6 years, 6-7 years and 7-8 years and 1 (1.0\%) each in 9-10 years, 10-11 years and 12-13 years (Table 2).

Table 1: Spectrum of accidental ingestion of hydrocarbons.

\begin{tabular}{|c|l|c|c|}
\hline Sl. No & Hydrocarbons & Number of patients (Total N = 118) & \% \\
\hline 1. & Diesel & 2 & 1.7 \\
\hline 2. & Petrol & 4 & 3.4 \\
\hline 3. & Turpentine & 7 & 6.0 \\
\hline 4. & Kerosene & 91 & 22.7 \\
\hline 5. & Miscellaneous & 14 & 11.9 \\
\hline
\end{tabular}

Table 2: Distribution of age.

\begin{tabular}{|c|l|c|c|}
\hline SL. No & Age (Years) & No. of children & \% \\
\hline 1. & Less than 1 & 4 & 3.3 \\
\hline 2. & 1 to 2 & 35 & 29.7 \\
\hline 3. & 2 to 3 & 11 & 9.3 \\
\hline 4. & 3 to 4 & 5 & 4.2 \\
\hline 5. & 4 to 5 & 2 in each group & 1.7 in Each group \\
\hline 6. & 5 to 6,6 to 7,7 to 8 & - & - \\
\hline 7. & 8 to 9 & 1 each in group & 1.0 in Each group \\
\hline 9. & $9-10,10$ to11 & - & - \\
\hline 10. & 11 to 12 & 1 & 1.0 \\
\hline 11. & 12 to 13 & - & \\
\hline
\end{tabular}

Among the HCs accidental ingestion of diesel (AID) was noted in only 2 children (1.7\%). Among these children with AID both were male children and they were of 1 year and 7 year old age. Among the HCs accidental ingestion of petrol (AIP) was noted in 4 (3.4\%). Among these children with AIP 1 child each of 2.5 years, 3 years, 6 years and 9 year old. Among the HCs accidental ingestion of turpentine (AIT) was noted in 7 (6\%). Among these children with AIT 2 children were in 1-2 and 3-4 age group and 1 each in 2-3, 4-5, ands 6-7 age group. No gender predominance were noted in children with AIT.

Among the HCs accidental ingestion of other miscellaneous HCs (AIM) were noted in 14 (11.9\%). Among these children with AIM majority 5 were in the age group between 2 to 3 years. Among these children with AIM 2 children were in 1-2 and 3-4 age group and 1 each in 1-2, 5-6 and 6-7 age groups. 3 were in 3-4 and 2 were in 4-5 age groups. Male children with AIM were $61.5 \%$ and females $38.5 \%$. Among the HCs accidental ingestion of kerosene (AIK) was noted in $91(22.7 \%)$. Among these children with AIK majority $47(51.6 \%)$ were in the age group between 2 to 3 years. 
Male children with AIK were $61.5 \%$ and females $38.5 \%$. Among the less than 1 year group included an 8 month old, 9 and 10 month old infants with AIK.

Table-3: Clinical manifestations of accidental ingestion of hydrocarbons.

\begin{tabular}{|c|l|c|}
\hline SL. No & Symptoms & $\mathbf{\%}$ \\
\hline 1. & vomiting and nausea & 69.5 \\
\hline 2. & Coughing & 63.6 \\
\hline 3. & Fever & 58.0 \\
\hline 4. & Tachypnoea & 19.5 \\
\hline 5. & Grunting & 17.8 \\
\hline 6. & Restlessness & 22.0 \\
\hline 7. & Drowsiness & 11.9 \\
\hline 8. & Cyanosis & 1.1 \\
\hline 9. & No symptoms & 12.7 \\
\hline
\end{tabular}

The common symptoms children had were vomiting and nausea $82(69.5 \%)$, coughing $75(63.6 \%)$, fever $68(58 \%)$, tachypnoea $23(19.5 \%)$, grunting 21(17.8\%), restlessness $26(22 \%)$ drowsiness $14(11.9 \%)$, cyanosis in one child and there were no symptoms in $15(12.7 \%)$ children (Table 3). The modified kuppuswamy scale was used to assess the socioeconomic status and majority of these children were from the lower socio-economic families. The incidence of AIH was highest in the months of April 27 (22.9\%) especially in the hot summer season in Kerala followed by the months of February $17(14.4 \%)$, May $16(13.6 \%)$ and June $14(11.9 \%)$ in these five year period of study analysing AIH in these children. All the patients were admitted to the PICU and all children with AIH were following oral ingestion. Complete hemogram done revealed leukocytosis in about $77 \%$ cases. Chest x ray were done in cases with AIH. 19 were normal and $99 \mathrm{c}$-xrays had varying degrees of infiltrations in the lung fields. The infiltrations in the majority were right-sided on analysing the c-xrays with varying degrees of lower lobe consolidation were seen more than the upper lobes in the cxrays. The sick child who had AIK with delayed presentation had massive consolidation of the right lung. 19 children after AIH had normal chest X-rays and were asymptomatic, probably as they had very minimal ingestion of HCs. Children with AIT also had only normal to minimal changes in the cxray. Most only required supportive care and these children were properly monitored. The clothes of these children contaminated with HCs were immediately removed to prevent absorption through skin. The children were given bath with soap and water to decontaminate skin and hair. Oxygen inhalation, proper hydration, antipyretics and antiemetics were given for the supportive care. Intravenous antibiotics started after the cxray showed infiltrations and consolidation in children with AIH. Gastric lavage was not done in any of these children with AIH. There was no mortality in our study.

\section{Discussion}

Accidental ingestion of poisonous substances and increase in the mortality is not only important in toxicology but also in the field of paediatrics and has been reported in the study in the best institutes of the country [1]. The paediatric population is very prone to the side effects and they suffer mainly due to their inquisitiveness. The incidence of accidental poisoning in children ranges from $7-8 \%[1,2]$. AIH is seen in children mostly who are younger than 5 years and among adolescents, who are more likely to abuse volatile HCs. Inhalant abuse with HCs is becoming increasingly common among adolescents as well. Literature review has shown that approximately $20 \%$ of students in middle school and high school have abused volatile substances especially volatile HCs [3]. The study highlights the AIH in the children admitted with poisoning in a private medical college in the state of Kerala having tertiary level care.
Hydrocarbons are a group of organic substances that are primarily composed of carbon and hydrogen molecules and are abundant in the nature. Among the HCs the most commonly seen are gasoline, petrol, diesel, lubricating oil, motor oil, mineral spirits, lighter fluid/naphtha, lamp oil, and kerosene [4]. Other common and miscellaneous sources of HCs include dry cleaning solutions, paint, spot remover, rubber cement and solvents. Some of these are volatile such as glue and propellants that contain HCs. The HCs can be derived from either petroleum or wood. Petroleum distillates include petrol, diesel, kerosene, gasoline, and naphtha, whereas turpentine and pine oil are obtained from wood. All the children with accidental ingestion of poisons were admitted initially in the PICU of the medical college. In this children 401 (6.9\%) were due to acute poisoning out of a grand total of 5806 admissions in the PICU in the period of five years of the study. 
In our study AIH was noted in 118 (29.4\%) of these children. This is in accordance with national and world wide studies conducted in children [1-4]. Most of the literature review with regards to $\mathrm{HC}$ poisoning reports a male predominance in the major studies in the population and younger age group than 5 years to be more susceptible to accidental poisoning $[1,2,4,5]$.

The toxicity of $\mathrm{HC}$ is directly related to their physical properties, specifically the viscosity, volatility, surface tension, and chemical activity of the side chains in their structure. The viscosity is the single most important chemical property associated with the aspiration risk [6]. HCs with a high volatility can vaporize and displace oxygen, which can lead to a transient state of hypoxemia.. The various human organ systems that can be affected by HCs include the pulmonary, neurologic, cardiac, gastrointestinal, hepatic, renal, dermatologic, and hematologic systems. The respiratory system is the most commonly involved system as in our retrospective study also. HC pneumonitis especially after aspiration results from a direct toxic affect by the $\mathrm{HC}$ on the lung parenchyma. The type II pneumocytes are the most affected, resulting in decreased production of surfactant. This decrease in surfactant, results in alveolar collapse, a ventilation-perfusion mismatch, and eventually hypoxemia. Hemorrhagic alveolitis that occurs subsequently peaks 3 days after ingestion and adds to the morbidity. The end result of $\mathrm{HC}$ aspiration is interstitial inflammation, intra-alveolar hemorrhage and edema, hyperemia, bronchial necrosis, and vascular necrosis. There are also rare pulmonary complications such as the development of a pneumothorax, pneumatocele, or bronchopleural fistula [7]. These children also can have central nervous system toxicity can result from several mechanisms, including direct injury to the brain or indirectly as a result of severe hypoxia or simple asphyxiation.It manifests as restlessness, delirium, stupor, lethargy and sometimes coma. Cardiotoxicity due to the side effects of HCs are also seen and this happens when the the myocardium becomes sensitized to the effects of catecholamines and results in, to tachydysrhythmias, syncope or sudden death [8]. HCs create a burning sensation as they irritating to the gastrointestinal mucosa. Vomiting has been reported in up to one third of all $\mathrm{HC}$ exposures as in our study also.The chlorinated HCs are hepatotoxic due to free radical formation unlike the aliphatic HCs in our study. The common histopathologic pattern is centrilobular (zone III) necrosis. Liver function test results can be abnormal within 24 hours after ingestion, and clinically apparent jaundice can occur within 48-96 hours but in our it was not noted as these agents were not ingested. Aromatic HC such as toluene can result in a distal renal tubular acidosis and anion gap acidosis but was not seen in our study. A patient may have chronic exposure either via an occupational environment or by repeated recreational inhalation. Hemolysis has been reported following the AIHs especially this group and benzene ingestion can lead to an increased risk of aplastic anemia, multiple myeloma, and acute myelogenous leukemia [9]. In our study the children had involvement of these systems and predominantly were having respiratory system involvement. This was seen in other studies as well [1-10].

The study done in 2004 and 2006 identifies AID in paediatrics and adult population as well $[11,12]$. Petrol as a cause of AIH was noted in other studies such as in a 23 year old adult and in a pregnant woman [13,14]. AIT in children is a problem of concern. Turpentine is seen as a major cause of ingestion in few studies[3,5]. Güzel A and Açıkgöz M. described in 2015 a case of AIT in a 9 year old child [15]. Rodricks A and Satyanarayana M reported in 2003 a 20-year old boy with turpentine-induced chemical pneumonitis that evolved into a bronchopleural fistula [16]. Monnet $\mathrm{P}$, Thome $\mathrm{J}$. reported poisoning by turpentine oil in a 23-month-old infant as early as in 1961 [17]. So this study is important as it is a common health hazard in our society. Among the HCs accidental ingestion of other miscellaneous HCs (AIM) were noted in 14 (11.9\%). The miscellaneous HCs were the following such as dry cleaning solutions, paint, spot remover, rubber cement and solvents. Some of these were volatile such as glue and propellants that contain HCs as was seen in a major study [18]. There have been many reports of AIK from worldwide and it is a common health hazard in children [1-10,19,20].

There are standard recommendations in the approach to a case of AIH.In all the cases of suspected AIH, it is important to determine the $\mathrm{HC}$ ingested, the route of ingestion (eg, oral, dermal, inhalational), the time and the quantity of $\mathrm{HC}$ ingested. In addition, the history should include enquiry about co-ingestants, any vomiting or coughing prior to admission at the hospital and whether any treatment given [21]. The physical examination should focus on the emergency triad ie about the patient's airway, breathing, and circulation (ABCs). The lung is the primary site of most common toxicity following $\mathrm{HC}$ exposures. The pulmonary symptoms (eg, coughing, gagging, choking) usually occur within 30 minutes of exposure but often can be delayed for several hours. Cutaneous irritation may result in erythema, blistering, pain, nasal dermatitis or perioral dermatitis (usually with chronic abuse.In our study all these symptoms were analysed. All the 
patients with $\mathrm{AIH}$ were admitted to the PICU. The causes of $\mathrm{HC}$ exposure are mainly accidental and especially in children. Due to the bad taste of the HC they ingest only small amounts and so they are rescued if brought to hospital soon after ingestion. But in grown up children they tend to take in large gulps of the $\mathrm{HC}$ due to thirst in a summer season mistaking for water and we had few cases similarly following AIK, AID, AID and AIM. Fortunately no mortality was seen in our study. Older adolescents take HCs for recreation to be in a state of euphoria but was absent in our study. Occupational exposure is common in adults. Oral ingestion intentionally for a suicide attempt was not seen in our study among these children. In our study all cases were admitted following ingestion and fortrunately there were no intentional poisoning as seen in other studies [10, 21]. Majority of these children were from the villages and rural areas around the medical college in central Kerala who belonged to lower socio-economic families. The HCs were kept in their houses for many household uses especially kerosene, but the others such as diesel and petrol were brought to house for the purpose as vehicle fuel. Turpentine was used for oiling and painting. The miscellaneous group of HCs included cleansing solutions and tile stain removers, washing agents. Kerosene was routinely used for cooking, heating and lighting the house. This was noted in studies by Cobaugh DJ et al in 2007 [22 ].

Complete hemogram done revealed leukocytosis in about $77 \%$ cases. The sick child who had AIK with delayed presentation had massive consolidation of the right lung. 19 children after AIH had normal chest xrays and were asymptomatic, probably as they had very minimal ingestion of HCs. Children with AIT also had only normal to minimal changes in the chest xray as seen in other studies [23,24]. Management for hydrocarbon intoxication is largely supportive as is mentioned in larger studies [21,25,26]. Most only required supportive care and these children were properly monitored in our study as well. The clothes of these children contaminated with $\mathrm{HCs}$ were immediately removed to prevent absorption through skin. Oxygen inhalation, proper hydration, antipyretics and antiemetics were given for the supportive care. Intravenous antibiotics started after the cxray showed infiltrations and consolidation in children with AIH. Gastric lavage was not done in any of these children with AIH. Steroids and their role is always highlighted in a case of AIH but in many literature review it is not having any role $[3,4,8,20-23,25,26]$. There was no mortality in our study of children with AIH.. As regard with the etiological agents involved, sixty two products were identified as various causes of acute poisoning. AIH was only second to drugs and medicines poisoning $128(28.7 \%)$ in the analysed data. AIH and poisoning occurs in poor families where it is used most frequently and ignorant parents. As most of the patients were from the villages and towns near to the medical college only positive aspect was that they did not delay in seeking help. Improper storage was the primary reason for ingestion. So a culturally appropriate regular home visits and educational programmes are needed to better prevent ingestion in young children [27].

\section{Conclusion}

Accidental childhood HC poisoning is a major health hazard. Prevention of AIH includes clearly labeling containers that contain HCs and also keep them away from paediatric population.Educating parents,teens and the community will surely help to prevent $\mathrm{AIH}$ and also reduce the morbidity due to AIH.

\section{Acknowledgement}

The authors acknowledge the help of the MRD section of the medical college for their help and support. Also express gratitude to house surgeons, post graduate students, nursing staff, colleagues for their timely help and to Dr Ajith TA, Professor, Biochemistry, Amala Institute of Medical Sciences, Amala Nagar, Thrissur, Kerala, India during the preparation of the manuscript. Above all, I am grateful to the almighty and my parents, my wife Sheena and daughters Sreelakshmi and Sreedevi without whose wishes and utmost sincere help, this work would not have seen the light of the day.

\section{Source of Support: Nil, Conflict of Interest: None Permission of IRB: Yes}

\section{References}

1. Srivastava A, Peshin SS, Kaleekal T, Gupta SK. An epidemiological study of poisoning cases reported to the National Poisons Information Centre, All India Institute of Medical Sciences, New Delhi. Hum Exp Toxicol. 2005 Jun;24(6):279-85.

2. Hyder AA, Wali S, Fishman S, Schenk E. The burden of unintentional injuries among the under-five population in South Asia . Acta Paediatrica. 2008 Mar; 97(3):267-275.

3. Anderson CE, Loomis GA. Recognition and prevention of inhalant abuse. Am Fam Physician. 2003 Sep 1;68(5):869-74.

4. Mowry JB, Spyker DA, Cantilena LR Jr, McMillan N, Ford M. 2013 Annual Report of the American 
Association of Poison Control Centers' National Poison Data System (NPDS): 31st Annual Report. Clin Toxicol (Phila). 2014 Dec. 52(10):1032-283.

5. Beamon RF, Siegel CJ, Landers G, Green V. Hydrocarbon ingestion in children: a six-year retrospective study. JACEP. 1976 Oct; 5(10):771-5.

6. Seymour FK, Henry JA. Assessment and management of acute poisoning by petroleum products. Hum Exp Toxicol. 2001 Nov; 20 (11):551-62.

7. Rodricks A, Satyanarayana M, D'Souza GA, Ramachandran P. Turpentine-induced chemical pneumonitis with broncho-pleural fistula. $J$ Assoc Physicians India. 2003 Jul; 51:729-30.

8. Klein BL, Simon JE. Hydrocarbon poisonings. Pediatr Clin North Am. 1986 Apr;33(2): 411-9.

9. Algren JT, Rodgers GC Jr. Intravascular hemolysis associated with hydrocarbon poisoning. Pediatr Emerg Care. 1992 Feb 8(1):34-5.

10. Siddiqui EU ${ }^{1}$, Razzak JA, Naz F, Khan SJ. Factors associated with hydrocarbon ingestion in children. J Pak Med Assoc. 2008 Nov; 58(11):608-12.

11. Benjelloun A, Ait Benasser MA Driouche A. Hydrocarbon pneumonitis. A case report. Rev Pneumol Clin. 2006 Jun; 62(3):191-4.

12. Khanna P, Devgan SC, Arora VK, Shah A.Hydrocarbon pneumonitis following diesel siphonage. Indian J Chest Dis Allied Sci. 2004 Apr-Jun; 46(2):129-32.

13. Janssen S, van der Geest S, Meijer S, Uges DR. Impairment of organ function after oral ingestion of refined petrol. Intensive Care Med. 1988; 14(3):238-40.

14. Fracas $\mathrm{M}$, Wabersich J. Petrol ingestion poisoning in a pregnant woman. Clin Exp Obstet Gynecol. 1997;24(4):223-5.

15. Güzel A, Açıkgöz M. A lethal danger in the home: turpentine poisoning. Turk J Pediatr. 2015 MarApr; 57(2):177-9.

16. Rodricks A, Satyanarayana M, D'Souza GA, Ramachandran P. Turpentine-induced chemical pneumonitis with broncho-pleural fistula. J Assoc Physicians India. 2003 Jul; 51:729-30.

17. Monnet $\mathrm{P}$, Thome J. Acute poisoning by turpentine oil in a 23-month-old infant Pediatrie. 1961;16:270-3.

18. Crosslin K, Tsai R.Unintentional ingestion of cleaners and other substances in an immigrant Mexican population: a qualitative study. Inj Prev. 2016 Apr;22(2):140-3. doi: 10.1136/injuryprev-2014-041446. Epub 2015 Mar 17.

19. Shotar AM:Kerosene poisoning in childhood: a 6year prospective study at the Princess Rahmat Teaching Hospital. Neuro Endocrinol Lett. 2005 Dec;26(6):835-8

20. Reed RP, Conradie FM.The epidemiology and clinical features of paraffin (kerosene) poisoning in rural African children. Ann Trop Paediatr. 1997 Mar;17(1):49-55.

21. Tormoehlen LM, Tekulve KJ, Nañagas KA. Hydrocarbon toxicity: A review. Clin Toxicol (Phila). 2014 Jun; 52(5):479-89.

22. Cobaugh DJ, Seger DL, Krenzelok EP.Hydrocarbon toxicity: an analysis of AAPCC TESS data. Przegl Lek. 2007; 64(4-5):194-6.

23. Sen V, Kelekci S, Selimoglu Sen H, Yolbas I, Günes A, Abakay O, Fuat Gurkan M. An evaluation of cases of pneumonia that occurred secondary to hydrocarbon exposure in children. Eur Rev Med Pharmacol Sci. 2013 Feb;17 Suppl 1:9-12.

24. Majeed HA, Bassyouni H, Kalaawy M, Farwana S. Kerosene poisoning in children: a clinico-radiological study of 205 cases. Ann Trop Paediatr. 1981 Jun;1(2):123-30.

25. Krenzelok EP New developments in the therapy of intoxications. ToxicolLett.2002Feb28;127(1-3):299-305.

26. Lamour C, Bouchaud C, Doré P, d'Arlhac M, Bodin J.Pneumonitis caused by hydrocarbon inhalationRev Mal Respir. 2003 Dec;20(6 Pt 1):959-64.

27. Munro S-A, Van Niekerk A, Seedat M. Childhood unintentional injuries: the perceived impact of the environment, lack of supervision and child characteristics. Child Care Health Dev. 2006 May;32:269-79.

\section{How to cite this article?}

Sunil Kumar M.N., Parvathy V. K. A study of accidental ingestion of hydrocarbons in children in a medical college hospital in central Kerala. Int J Pediatr Res 2016;3(5):297-302.doi:10.17511/ijpr.2016.i05.05 